\title{
HUBUNGAN GANGGUAN POLA TIDUR DENGAN HIPERTENSI LANSIA DI DESA SEI KAPITAN KABUPATEN KOTA WARINGIN BARAT (Studi di Desa Sei Kapitan Kotawaringin Barat)
}

\author{
Devi Arissandi ${ }^{1}$ Agung Setyono Wibowo $^{2}$ Eny Lestari $^{3}$ \\ ${ }^{1}$ STIKes Insan Cendekia Medika Jombang ${ }^{23}$ STIKes Borneo Cendekia Medika \\ Pangkalan Bun \\ 1email : deviarissandi@gmail.com, ${ }^{2}$ email : agungwibowo@gmail.com, ${ }^{3}$ email : \\ enylestari@gmail.com
}

\begin{abstract}
ABSTRAK
Pendahuluan: Tidur merupakan kebutuhan dasar manusia agar memiliki fungsi tubuh yang optimal. gangguan pola tidur yang meningkat dapat mengaktivasi sistem saraf simpatis yang akhirnya menyebabkan peningkatan tekanan darah. Penelitian ini bertujuan untuk mengetahui apakah ada hubungan antara gangguan pola tidur hipertensi lansia di Desa Sei Kapitan Kabupaten Kota Waringin Barat. Metode penelitian: Jenis penelitian ini merupakan penelitian kuantitatif dengan menggunakan desain cross-sectional. Populasi pada penelitian ini berjumlah 30 orang dengan menggunakan teknik total sampling. Data analisis bivariat dengan menggunakan uji korelasi rank Spearman. Hasil penelitian: Gangguan pola tidur meningkat sebanyak 15 orang (50\%) dan hipertensi sebanyak 17 orang $(56,7 \%)$. Sedangkan responden di Desa Sei Kapitan Kotawaringin Barat pada gangguan pola tidur meningkat dan terjadinya hipertensi sebanyak 12 orang (40\%) dan dengan hasil rank spearman 0,007 menunjukan nilap P < 0,05 menunggunakan aplikasi SPSS 16. Kesimpulan: Berdasarkan hal tersebut dapat disimpulkan bahwa ada hubungan yang signifikan antara gangguan pola tidur dengan hipertensi lansia.
\end{abstract}

Kata kunci : Gangguan Pola Tidur, Hipertensi.

\section{RELATIONSHIP DISTURBANCE OF SLEEP PATTERNS WITH ELDERLY HYPERTENSION IN THE VILLAGE SEI KAPITAN KABUPATEN KOTAWARINGIN BARAT (Study in the village Sei Kapitan Kotawaringin Barat)}

\section{ABSTRACT}

Introduction: Sleep is a basic human need to have optimal body function. Increased sleep patterns disorder can activate the sypatthetic nervous system that ultimately leads to increased blood pressure. This study aims to determine whether there is a relationship between disturbance of sleep patterns of elderly hypertension in the village Sei Kapitan Kotawaringin Barat. Research Method: This type of research is a quantitative study using cross-sectional design. The population in this study amounted to 30 people using the technique of total sampling sempel. Data of 
bivariate analysis using correlation test of rank spearmen. Result: Slepp disorders increased by 15 people (50\%) and hypetension by 17 (56,7\%). While the respondents in the village Sei Kapitan Kotawaringin Barat on sleep disorder increased an the accurrence of hypertension as many as 12 people (40\%) and with the result rank spearmaen 0,007 showed value $p<0,05$ using application of SPSS 16. Conclusion: Based on it can be concluded there is a significant realitionship beween sleep disorder whit hypertension elderly.Suggestion:

Keywords : Sleep Disorder, Hypertension

\section{PENDAHULUAN}

Hipertensi disinyalir hampir menyerang pada satu miliar orang didunia. Penyakit ini jika dibiarkan terus-menerus akan menimbulkan dampak yang sangat merugikan bahkan dapat berujung pada kematian. Penyakit tidak menular ini menjadi ancaman yang menakutkan bagi siapa saja. Karena tidak dapat disembuhkan hal yang harus dilakukan adalah melakukan kontrol rutin untuk menjaga tekanan darah dalam rentang yang cukup stabil serta melakukan gaya hidup sehat. Hal ini dapat menjaga organ yang berkaitan seperti jantung dan otak tidak mengalami kerusakan atau kelainan yang diakibatkan oleh peningkatan tekanan darah ini. (Agoes, 2008 dalam Yusuf, 2013, 6).

World Health Organization (WHO) menyebutkan bahwa dari $70 \%$ penderita diseluruh dunia yang tidak melakukan pengobatan dengan benar sebanyak $25 \%$ serta hanya sebanyak $12,5 \%$ yang melakukan pengobatan dengan baik dan rutin. Penderita hipertensi diproyeksikan akan terus bertambah sebanyak $60 \%$ atau dengan kata lain akan menyerang 1,56 miliar penduduk dunia hingga tahun 2025 (WHO dalam Widyastuti, 2015, 1). Penderita hipertensi di Indonesia sendiri berada diantara $17-21 \%$ dari jumlah penduduk dan data tersebut masih diperkirakan dapat bertambah karena banyak sekali penderita hipertensi yang belum terdeteksi bahkan beberapa orang tidak tau mengenai kondisi mereka. (Maharani, 2013, 4). Di Jawa Tengah sendiri penderita hipertensi sudah memasuki angka 26,4\% (Kemenkes RI, 2013, 102).

Minuman keras, rokok dan makanan atau minuman yang mengandung kafein tinggi dapat menjadi faktor yang dapat mendorong peningkatan tekanan darah ini menjadi semakin parah (Marliani dan Tantan, 2007, 27). Hipertensi yang dibiarkan semakin lama dapat menjadi pemicu terjadinya penyakit kardiovaskuler seperti serangan jantung maupun stroke. Hal ini sejalan dengan kemauan penderita yang masih kurang dalam melakukan pengecekan secara rutin pada hipertensi yang dialaminya (Pradono, et all, 2012, 61). Pada masa lansia banyak sekali hal-hal yang berubah dalam tubuh seseorang, baik itu dari segi fisiologis maupun psikologis. Pada segi psikologis mereka sering beranggapan bahwa mereka mulai kehilangan pekerjaan, teman, dan status yang mereka miliki. Mereka terkadang merasakan cemas terhadap kematian yang akan dialaminya sehingga hal ini dapat memunculkan berbagai masalah salah satunya gangguan pada pola tidur (Maryam, 2008, dalam Dhin, 2015, 
16). Seiring usia yang mulai bertambah gangguan pada tidur akan semakin intens terjadi. Mereka yang berusia diatas 40 tahun akan memiliki kualitas tidur yang semakin berkurang hal ini dapat disebabkan oleh berbagai penyakit yang mengiringinya.Tidur merupakan suatu hal yang sifatnya alamiah dan tidur juga merupakan kebutuhan yang harus dipenuhi oleh setiap individu. saat tidur terjadi perbaikan dan pembaruan sel-sel dan menjaga metabolisme tubuh tetap terjaga dengan baik.(Noviani, et all, 2011, 6).

Lansia cenderung menyukai makanan yang memiliki cita rasa kuat seperti manis, asin, bahkan gurih. Hal ini karena kemampuan dalam merasakan rasa mulai mengalami penurunan. Lansia yang cenderung menyukai makanan asin dan berlemak dapat beresiko lebih tinggi meningkatkan tekanan darahnya karena natrium yang terkandung dalam garam akan mengikat air dan semakin menambah jumlah darah. Dengan meningkatnya volume maka kerja jantung akan semakin berat dalam memompa dan mengatur aliran darah. Maka dari itu bisa menyebabkan hipertensi (Yekti, 2011, 60).

\section{METODE PENELITIAN}

Penelitian ini merupakan korelasi dengan jenis penelitian ini adalah penelitian kuantitatif. Desain penelitian yang digunakan cross-sectional. Penelitian ini berlangsung pada April s/d Juni 2019. Populasi dalam penelitian ini adalah lansia baik lakilaki maupun perempuan di desa Sei Kapitan yang berjumlah 30 lansia. Teknik sampling yang digunakan yaitu Total Sampling sehingga sampel dalam penelitian ini adalah seluruh lansia yang berjumlah 30 orang. Instrumen pada penelitian ini adalah kuesioner yang sudah diuji validitas dan reliabilitas serta pengukuran tekanan darah menggunakan tensi meter dan stetoskop. Variabel independen penelitian ini adalah gangguan pola tidur dan dependennya adalah hipertensi. Analisa data uji Rank Spearman dengan $\alpha=0,05$.

\section{HASIL PENELITIAN}

\section{Data Umum}

Tabel 1 distribusi frekuensi berdasarkan jenis kelamin Desa Sei Kapitan Kota Waringin Barat $(n=30)$

\begin{tabular}{ccc}
\hline $\begin{array}{c}\text { Jenis } \\
\text { kelamin }\end{array}$ & Jumlah & Persentase (\%) \\
\hline Laki-laki & 14 & $46,7 \%$ \\
Perempuan & 16 & $53,3 \%$ \\
\hline Total & 30 & $100 \%$ \\
\hline
\end{tabular}

Sumber : Data Primer Mei 2019

Pada tabel 1 menunjukan bahwa sebagian besar jenis kelamin lansia di desa sei kapitan kotawaringin barat adalah 16 perempuan sebayak orang $(53,3 \%)$

Tabel 2 distribusi frekuensi berdasarkan usia desa sei kapitan kota waringin barat $(n=30)$

\begin{tabular}{ccc}
\hline $\begin{array}{c}\text { Umur } \\
\text { (tahun) }\end{array}$ & Jumlah & $\begin{array}{c}\text { Persentase } \\
(\%)\end{array}$ \\
\hline $55-57$ & 9 & $30 \%$ \\
$58-60$ & 13 & $43,3 \%$ \\
$61-64$ & 8 & $26,7 \%$ \\
\hline Total & 30 & $100 \%$ \\
\hline
\end{tabular}

Sumber : Data Primer Mei 2019

Pada tabel 2 menunjukan bahwa hampir setengahnya umur lansia adalah 58-60 tahun sebayak 13 orang (43,3\%). 
Tabel 3 distribusi frekuensi berdasarkan pendidikan Desa Sei Kapitan Kota Waringin Barat $(n=30)$

\begin{tabular}{ccc}
\hline Pendidikan & Jumlah & Persentase (\%) \\
\hline Tidak sekolah & 14 & $46,7 \%$ \\
TK & 7 & $23,3 \%$ \\
SD & 6 & $20 \%$ \\
PT & 3 & $10 \%$ \\
\hline Total & 30 & $100 \%$ \\
\hline
\end{tabular}

Sumber : Data Primer Mei 2019

Pada tabel 3 menunjukan bahwa hamper setengahnya pendidikan lansia adalah tidak sekolah sebayak 14 orang $(46,7 \%)$.

Tabel 4 distribusi frekuensi berdasarkan pekerjaan lansia di Desa Sei Kapitan Kota Waringin Barat $(n=30)$

\begin{tabular}{ccc}
\hline Pekerjaan & Jumlah & Persentase $(\%)$ \\
\hline Petani & 11 & $36,7 \%$ \\
Buruh & 15 & $50 \%$ \\
Wiraswasta & 1 & $3,3 \%$ \\
PNS & 3 & $10 \%$ \\
\hline Total & 30 & $100 \%$ \\
\hline
\end{tabular}

Sumber : Data Primer Mei 2019

Pada tabel 4 menunjukan bahwa sebagian besar pekerjaan lansia di desa sei kapitan kotawaringin barat adalah buruh sebayak 15 orang $(23,3 \%)$.

\section{Data Khusus}

Tabel 5 gangguan pola tidur lansia di Desa Sei Kapitan Kota Waringin Barat tahun $2019(\mathrm{n}=30)$

\begin{tabular}{ccc}
\hline $\begin{array}{c}\text { Gangguan } \\
\text { pola tidur }\end{array}$ & Frekuensi & $\begin{array}{c}\text { Persentase } \\
(\%)\end{array}$ \\
\hline Meningkat & 15 & $50 \%$ \\
Normal & 12 & $40 \%$ \\
Menurun & 3 & $10 \%$ \\
\hline Total & 30 & $100 \%$ \\
\hline Sumber : Data Primer Mei 2019 &
\end{tabular}

Pada tabel 5 menunjukan bahwa sebagian besar gangguan pola tidur meningkat lansia di desa sei kapitan kotawaringin barat adalah meningkat sebayak 15 orang $(50 \%)$.

Tabel 6 hipertensi lansia di desa sei kapitan kota waringin barat tahun 2019 $(\mathrm{n}=30)$

\begin{tabular}{ccc}
\hline $\begin{array}{c}\text { Hipertensi } \\
\text { lansia }\end{array}$ & Frekuensi & $\begin{array}{c}\text { Perentase } \\
(\%)\end{array}$ \\
\hline Normal & 9 & $30 \%$ \\
Prehipertensi & 4 & $13,3 \%$ \\
Hipertensi & 17 & $56,7 \%$ \\
\hline Total & 30 & $100 \%$ \\
\hline Sumber : Data Primer Mei 2019 &
\end{tabular}

Pada tabel 6 menunjukan bahwa sebagian besar hipertensi lansia di desa sei kapitan kotawaringin barat adalah hipertensi sebayak 17 orang $(56,7 \%)$.

Tabel 7 distribusi frekuensi gangguan pola tidur dengan hipertensi lansia

\begin{tabular}{ccccccccc}
\hline \multirow{2}{*}{$\begin{array}{l}\text { Gangguan } \\
\text { pola tidur }\end{array}$} & \multicolumn{6}{c}{ Hipertensi } & \multirow{2}{*}{ Total } \\
\cline { 2 - 8 } & Baik & \multicolumn{3}{c}{ Sedang } & Buruk & \\
\cline { 2 - 7 } & $\mathrm{N}$ & $\%$ & $\mathrm{~N}$ & $\%$ & $\mathrm{~N}$ & $\%$ & $\mathrm{~N}$ & $\%$ \\
\hline Meningkat & 2 & 6,7 & 1 & 3,3 & 12 & 40 & 15 & 50 \\
Normal & 5 & 16,7 & 3 & 10 & 4 & 13,3 & 13 & 40 \\
Menurun & 2 & 6,7 & 0 & 0 & 1 & 3,3 & 3 & 10 \\
\hline Total & 9 & 30 & 4 & 13,3 & 17 & 56,6 & 30 & 100 \\
\hline \multicolumn{6}{c}{ Rank spearman $=0,007$} \\
\hline Sumber : Data Primer Mei 2019
\end{tabular}

Pada tabel 7 diatas menunjukan bahwa hampir setengahnya lansia pada gangguan pola tidur meningkat dan terjadi hipertensi sebayak 12 orang (40\%). Hasil uji statistik rank spearman dengan SPSS 16 dihasilkan nilai $\mathrm{p}=0,007$. Pada penelitian ditetapkan derajat error $\alpha=0,05$. Setelah dibandingkan diperoleh $\mathrm{p}<\alpha$, sehingga Ho ditolak dan H1 diterima maka dapat dikatakan ada hubungan gangguan pola tidur dengan hipertensi pada lansia. 


\section{PEMBAHASAN}

\section{Gangguan pola tidur}

Pada tabel 5 didapatkan setenganya responden meningkat dalam gangguan pola tidur nya sebayak $50 \%$ atau 15 orang.

Peneliti berpendapat usia yang semakin bertambah dapat menggangu pola dan kualitas tidur pada lansia selain itu faktor yang dialaminya misalnya pekerjaan dan penyakit yang mengiringinya.

Tidur yang cukup dapat memulihkan tenaga. Tidur dapat memberikan waktu untuk perbaikan dan penyembuhan sistem tubuh untuk periode keterjagaan berikutnya. Selama penuaan terjadi perubahan fisik dan mental yang diikuti dengan perubahan pola tidur yang khas yang membedakan dari orang yang lebih muda. Kebutuhan tidur orang berbeda beda, untuk usia lanjut membutuhkan waktu tidur 6-7 jam per hari (Widyastuti, 2015, 9).

\section{Hipertensi}

Pada tabel 6 menunjukan bahwa sebagian besar lansia mengalami hipertensi sebanyak 17 orang $(56,7 \%)$.

Menurut peneliti pola tidur dapat menjadi faktor pemicu karena hal ini mempengaruhi bagaimana pelebaran dan penyempitan pembuluh darah. Selain itu faktor jenis kelamin dan pendidikan juga dapat menjadi faktor pendukung meningkatnya tekanan darah diatas ambang normal atau hipertensi

Hipertensi merupakan meningkatnya tekanan darah arteri dengan sistol yaitu
$140 \mathrm{mmHg}$ atau lebih dan diastol sebanyak $90 \mathrm{mmHg}$ atau lebih. Semakin tinggi pendidikan seseorang maka akan semakin mudah dalam memahami informasi, sehingga seseorang dapat mencegah perilaku beresiko hipertensi (Notoatmodjo, 2010 dalam Widyastuti, 2015, 51).

\section{Hubungan gangguan pola tidur dengan hipertensi lansia}

Pada tabel 7 diatas menunjukan bahwa hamper setengahnya lansia pada gangguan pola tidur meningkat dan terjadi hipertensi sebayak 12 orang (40\%). Hasil rank spearmen test dengan bantuan SPSS didapatkan nilai $\mathrm{p}=0,007$. Pada penelitian ditetapkan derajat error $\alpha=0,05$. Setelah dibandingkan diperoleh $\mathrm{p}<\alpha$, sehingga Ho ditolak dan H1 diterima maka dapat dikatakan ada hubungan gangguan pola tidur dengan hipertensi pada lansia.

Peneliti berasumsi bahwa pola tidur yang kurang baik dapat mempengaruhi tekanan darah karena hal ini akan mempengaruhi metabolisme dalam tubuh terutama dalam hal pengeluaran hormon yang dapat memicu meningkatnya tekanan darah. Lansia sering mengalami gangguan pola tidur karena mereka tiba-tiba dapat terbangun pada malam hari.

Hipertensi dapat dipengaruhi oleh beberapa faktor resiko yaitu riwayat keluarga, kebiasaan hidup yang kurang baik, pola diit dan kualitas tidur. Durasi dan kualitas tidur yang kurang baik dapat memicu aktivitas sistem saraf simpatik dan menimbulkan stressor fisik dan psikologis (Lloyd-Jones, et all, 2010 dalam Widyastuti 2015, 55). Lansia yang mengalami gangguan pola 
tidur dapat mengakibatkan hormon angiotensin meningkat, hormon inilah yang bertanggung jawab dalam meningkatnya tekanan darah (Widyastuti, 2015, 57).

\section{KESIMPULAN DAN SARAN}

\section{Kesimpulan}

1. Gangguan pola tidur pada lansia di Sei Kapitan Kabupaten Kotawaringin Barat tahun 2019 didapatkan hasil setengah lansia memiliki gangguan pola tidur meningkat sebayak 15 orang (50 $\%)$.

2. Hipertensi pada lansia di Sei Kapitan Kabupaten Kotawaringin Barat tahun 2019 mendapatkan hasil sebagian besar lansia memiliki hipertensi sebayak 17 orang $(56,7$ $\%)$.

3. Ada hubungan antara gangguan pola tidur dengan hipertensi lansia. di Desa Sei Kapitan Kotawaringin Barat tahun 2019 nilai $\mathrm{p}=0,007$.

\section{Saran}

1. Bagi Masyarakat

Diharapkan masyarakan dapat menggali informasi mengenai hipertensi dan faktor-faktor yang dapat menjadi pemicu maupun pendorong meningkatnya tekanan darah serta melakukan perbaikan pada gaya hidup seperti memperbaiki pola makan maupun kebutuhan tidur mereka.

2. Bagi Lansia

Diharapkan pasien dapat menjaga pola tidur dan menghindari faktor- faktor pemicu maupun pendorong agar hipertensi yang dialami dapat mengalami penurunan.

3. Peneliti Selanjutnya

Diharapkan peneliti selanjutnya dapat melakukan penelitiaan mengenaai terapi yang efektif untuk menurunkan gangguan tidur dan tekanan darah.

\section{DAFTAR PUSTAKA}

Dhin, Ayu Fiaka. 2015. Hubungan tingkat kecemasan dengan kejadian insomnia pada lanjut usia di Posyandu Lansia Flamboyan Dusun Jetis Tamantirto Kasihan Bantul Yogyakarta. UNISAYOGYA: Yogyakarta.

Kementerian Kesehatan RI. 2014. Profil Kesehatan Indonesia Tahun 2013. Jakarta : Kementerian Kesehatan RI. Diakses dalam http://www.depkes.go.id/resour ces/download/pusdatin/profilke sehatan-indonesia/profilkesehatan-indonesia-2013. Pukul 12.00 WIB.

Maharani, C. and Darmawan, S., 2013. "Pengaruh Penyuluhan Kesehatan Terhadap Pengetahuan Masyarakat Tentang Penyakit Hipertensi di Desa Patobong Kecamatan Mattiro Sompe Kabupaten Pinrang". STIKES Nani Hasanudin: Makassar.

Majid, YA. 2014. "Pengaruh Akupresur Terhadap Kualitas Tidur Lansia di Balai Perlindungan Sosial Tresna Werdha Ciparay". Program 
Studi Magister Keperawatan Fakultas Ilmu Keperawatan Universitas Padjadjaran: Bandung.

Marliani, L. and Tantan, S., 2007. 100 Questions dan Answers Hipertensi. Jakarta: PT Elex Media Komputindo.

Noviani, Okti; Handayani, Safrudin. 2011. Hubungan Lama Tidur Dengan Perubahan Tekanan Darah Pada Lansia Dengan Hipertensi di Posyandu Lansia Desa Karangaren. Jurnal Ilmiah Kesehatan Keperawatan. Vol 7 No. 2

Pradono, J., Indrawati, L. and Murnawan, T., 2013. Permasalahan Dan Faktor Risiko Yang Berhubungan Dengan Terjadinya Hipertensi Di Kabupaten Bogor Prov. Jawa Barat. Buletin Penelitian Kesehatan, 41(2 Juni).

Widyastuti, Yuni. 2015. Studi Komparasi Tekanan Darah Penderita Hipertensi yang Mengkonsumsi Semangka di Kelurahan Patangpuluhan Wirobrajan

Yogyakarta (Doctoral dissertation, STIKES'Aisyiyah Yogyakarta).

Yekti, D. and Wulandari, A., 2011. Cara Jitu Mengatasi Hipertensi. Jakarta: Andi Publisher.

Yusuf, Dewi Yulyan Nur. 2013. Gambaran Perilaku Penderita Hipertensi Dalam Upaya Mencegah Kekambuhan Penyakit Hipertensi Di Wilayah Kerja Puskesmas Dulalowo Kota
Gorontalo Tahun 2013. UNG: Gorontalo. 